Article

\title{
FlexFlax Stool: Validation of Moldless Fabrication of Complex Spatial Forms of Natural Fiber-Reinforced Polymer (NFRP) Structures through an Integrative Approach of Tailored Fiber Placement and Coreless Filament Winding Techniques
}

\author{
Vanessa Costalonga Martins ${ }^{1}$, Sacha Cutajar ${ }^{1}$, Christo van der Hoven ${ }^{1}$, Piotr Baszyński ${ }^{2, *(D)}$ \\ and Hanaa Dahy ${ }^{2,3}$ \\ 1 ITECH Masters Program, University of Stuttgart, Keplerstr. 11, 70174 Stuttgart, Germany; \\ costalonga.v@gmail.com (V.C.M.); cutajar.sacha@gmail.com (S.C.); \\ christovanderhoven@gmail.com (C.v.d.H.) \\ 2 BioMat Department: Bio-Based Materials and Materials Cycles in Architecture, Institute of Building \\ Structures and Structural Design, University of Stuttgart, Keplerstr. 11, 70174 Stuttgart, Germany; \\ hanaa.dahy@itke.uni-stuttgart.de \\ 3 Faculty of Engineering, Department of Architecture (FEDA), Ain Shams University, Cairo 11517, Egypt \\ * Correspondence: piotr.baszynski@itke.uni-stuttgart.de
}

Received: 1 April 2020; Accepted: 29 April 2020; Published: 8 May 2020

\begin{abstract}
It has become clear over the last decade that the building industry must rapidly change to meet globally pressing requirements. The strong links between climate change and the environmental impact of architecture mean an urgent necessity for alternative design solutions. In order to propose them in this project, two emergent fabrication techniques were deployed with natural fiber-reinforced polymers (NFRPs), namely tailored fiber placement (TFP) and coreless filament winding (CFW). The approach is explored through the design and prototyping of a stool, as an analogue of the functional and structural performance requirements of an architectural system. TFP and CFW technologies are leveraged for their abilities of strategic material placement to create high-performance differentiated structure and geometry. Flax fibers, in this case, provide a renewable alternative for high-performance yarns, such as carbon, glass, or basalt. The novel contribution of this project is exploring the use of a TFP preform as an embedded fabrication frame for CFW. This eliminates the complex, expensive, and rigid molds that are traditionally associated with composites. Through a bottom-up iterative method, material and structure are explored in an integrative design process. This culminates in a lightweight FlexFlax Stool design (ca. $1 \mathrm{~kg}$ ), which can carry approximately 80 times its weight, articulated in a new material-based design tectonic.
\end{abstract}

Keywords: natural fiber-reinforced polymers; NFRP; computational design; tailored fiber placement; coreless filament winding; rapid prototyping; industry 4.0; lightweight structure

\section{Introduction}

The environmental impact of commercial construction and fabrication methods has been well documented. The built environment, for instance, accounts for $36 \%$ of global energy use, with cement alone contributing to $8 \%$ of annual global carbon dioxide production [1-3].

The creation of complex forms, be it a wall or a chair, can become an especially resource-intensive exercise. This expense is not only in terms of the embodied energy of the artefact itself but also the process required to produce it. This often occurs when materials are deployed in a simple, homogenous, 
top-down manner. This is not a new problem, nor is it trivial, and there are a number of attitudes for using materials more responsibly. Some strategies come from incremental technological development, whilst others adopt techniques, technologies, and ideas from other industries, opening the door to new possibilities [4]. It is appropriate, then, to investigate how these alternative approaches may translate into more harmonious architectural design solutions.

Fiber-reinforced composites (FRCs) have been well used in the automotive, nautical, and aerospace industries over the last decades, but less so in architecture and product design. In contrast to some other processes, working with composites can allow for the strategic placement of material to create differentiated structure and geometry. This is typically done in an additive process and can result in products with a high specific strength. A superior strength-to-weight ratio can, in turn, translate into reduced material use, as well as reduced use of supporting materials, such as concrete or metals [5].

Two particularly novel composite fabrication methods for FRCs are coreless filament winding (CFW) and tailored fiber placement (TFP). Both processes have great potential at the architectural scale. These techniques deploy numerically-controlled machines in digital design workflows for precision, efficiency, and mass-customization [6,7]. However, both CFW and TFP still used complicated and resource-intensive fabrication frames or molds during production (Figure 1).

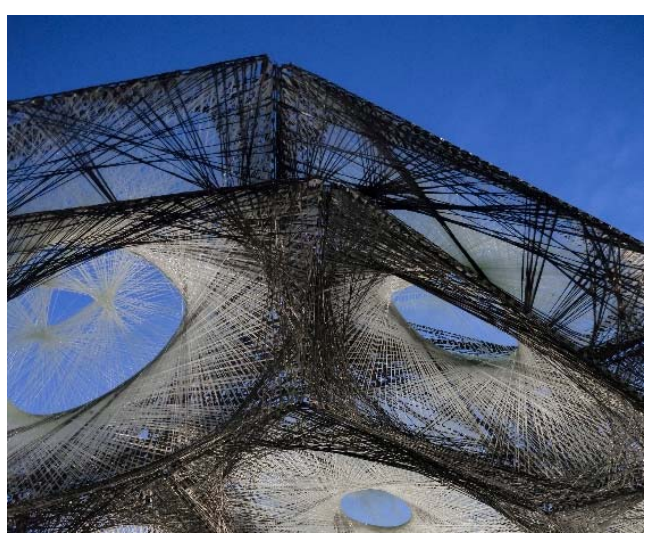

(a)

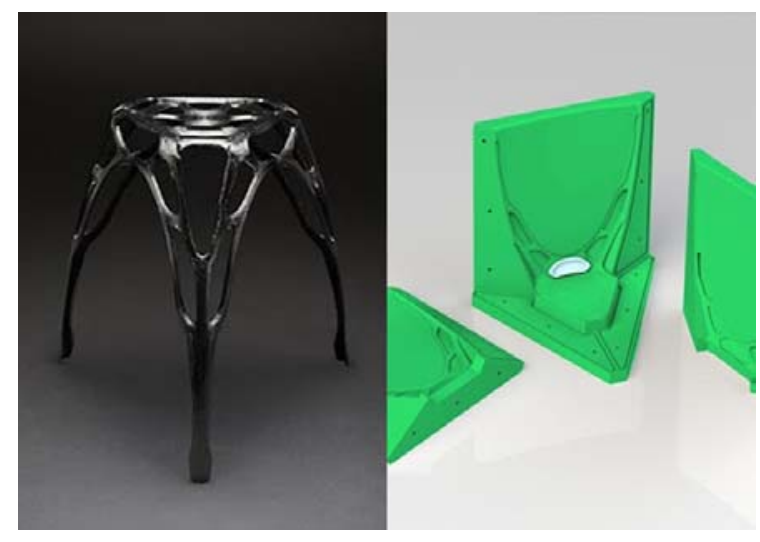

(b)

Figure 1. Fabrication frames and molds: (a) coreless filament winding (CFW); the Institute for Computational Design/the Institute of Building Structures and Structural Design (ICD/ITKE) Research Pavilion 2013-14 and its module edges shaped by a complex reconfigurable steel filament winding frame [9]; (b) tailored fiber placement (TFP); the L1 Lightweight Stool alongside its elaborate rigid mold [8].

For almost 10 years, the Institute for Computational Design (ICD), the Institute of Building Structures and Structural Design (ITKE), and, more recently, the BioMat group at ITKE (the Department of Biobased Materials and Materials Cycles in Architecture) at the University of Stuttgart, have investigated composites through the lenses of computation, digital design and fabrication, structure, and sustainability. Their research has not been limited to conventional FRC based on carbon fibers (CFs) and glass fibers (GFs), but also explored possibilities of replacing them with fibers from annually renewable resources, such as flax and hemp, as well as with agricultural residues, namely straw, for the purpose of developing structural systems based on natural fiber-reinforced polymers (NFRPs) [8]. Through a multifarious series of temporary pavilions, demonstrators, seminars, and research projects, the potential of these materials at an architectural scale have been investigated [5,6]. This project dives deeper into this research context, building on the pioneering work of these institutes. The corresponding precedent projects shown below should additionally be understood through the broader goal of this project and the design and prototyping of a stool.

In their project "Tailoring Self-Formations", Aldinger and Margariti explored carbon fiber bending elements sewn onto a prestressed membrane substrate (Figure 2a). The self-formation process was driven 
by the release of the prestress in the membrane, which in turn acted as an actuator. The actuation sent the CFP elements into bending, determined by specific predefined 2D geometries, thereby predictably creating complex double-curved surfaces without the need for a mold. This project illustrates the possibility of creating complex forms in mold-less TFP fabrication, as well as fiber-reinforced composites (FRCs) in bent states of compound Gaussian curvature [10].

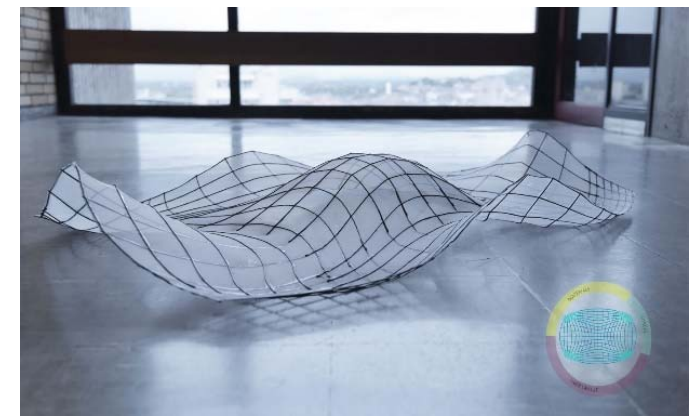

(a)

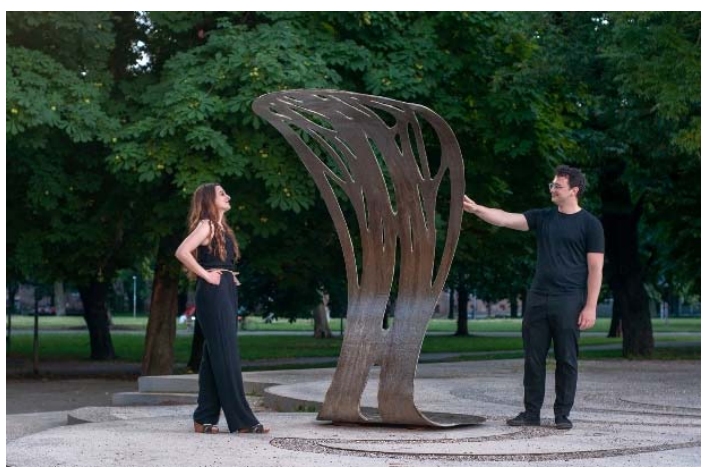

(c)

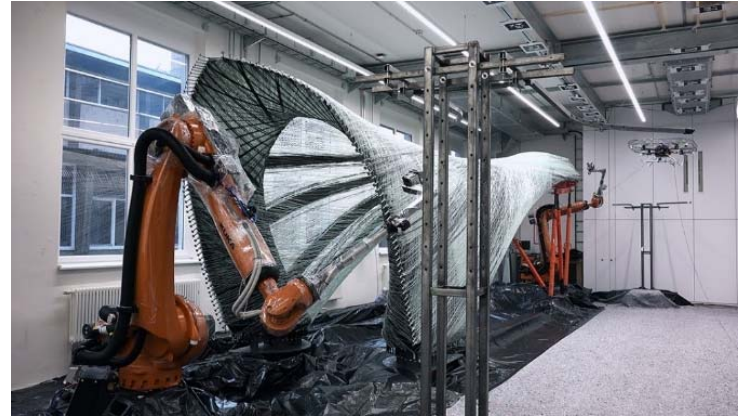

(b)

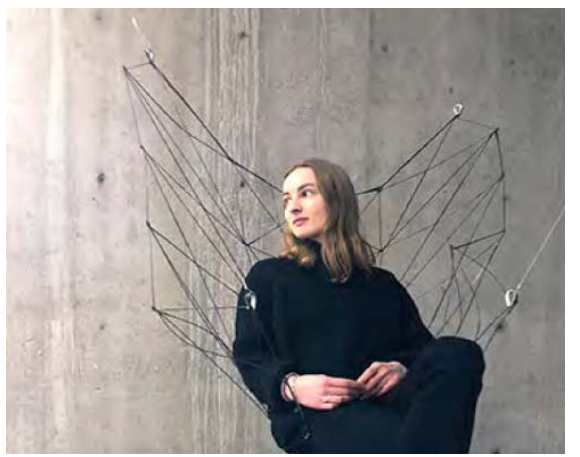

(d)

Figure 2. State-of-the-art: (a) "Tailoring Self-Formations" [10]; (b) "ICD/ITKE Research Pavilion 2016-17" [11]; (c) “Tailored Biocomposite Mock-up of BioMat 2019" [12]; (d) "Aerochair" [13].

The ICD/ITKE Research Pavilion 2016-17 is a good precedent of a biomimetic transfer for an embedded bending active filament winding frame (Figure $2 b$ ). In this case, the biological role model was the leaf miner moth (Lyonetia clerkella), which bends a leaf into shape with its silk and then uses the resulting geometry as the environment to create a cocoon. The abstracted fabrication process starts with a flat CFW preform, which is bent into shape, becoming the winding scaffold for the main layers of structural filaments of the demonstrator. In this case, the ratio of the winding frame to the CFW component was minimal. Additionally, a substantial portion of the fabrication setup remained embedded within the structure, taking on an additional function [11].

In 2019, BioMat successfully attempted to realize a small scale monolithic NFRP canopy using TFP preforms for precise control of fiber orientation in the structure (Figure 2c). Rhinoceros 3D plugins (Grasshopper, Galapagos and Millipede) used in the initial form-finding process of this lightweight canopy allowed us to define the most deformation-resistant geometry. Further topological optimization of the structure was conducted using Matlab and an agent-based system tool created using processing. This allowed us to calculate the optimum flax fiber paths orientation on the whole structure surface to be realized at a later TFP fabrication stage. Secondly, the structure was tessellated into several overlapping layers consisting of multiple preforms no larger than $1.0 \times 1.4 \mathrm{~m}$. This size limitation was imposed by the working area of the Tajima TFP embroidery machine, offered by the Institute of Aircraft Design (IFB) at the University of Stuttgart. Finally, all preforms were placed on a mold, custom-made using CNC-milled elements, for a vacuum-assisted resin transfer molding (VARTM) process [12]. A tailored biocomposite mock-up of BioMat 2019 proved the applicability of TFP fabrication in structural projects 
requiring topological optimization. However, at the same time, it exposed the necessity of developing alternative, more resource-efficient solutions to complex 3D molds used in the VARTM process.

Finally, Duque Estrada and Wyller investigated design methodologies for CFW of carbon fiber for ultra-lightweight furniture design (Figure 2d). Their "Aerochair" used the high tensile strength of carbon rovings as the primary design driver. "By allowing the chair to hang, instead of stand, a new design expression that properly conveys the material characteristics presents itself" [13]. This project successfully demonstrates the use of continuous resin-impregnated carbon fiber yarns, with the furniture piece weighing only $300 \mathrm{~g}$. However, the fabrication process still requires a large and complex frame. Furthermore, the novel hanging typology may not be a fully representative portrayal of a load-bearing architectural system, which must typically accommodate compression and bending in addition to tension. Consequently, there still remains significant terrain for further investigation.

Therefore, the aim of this project was to create a stool with coreless filament winding and tailored fiber placement of resin-impregnated, continuous natural fiber yarn without the use of a complicated mold or frame. The design and physical production of a small furniture piece was used as a means to engage the research context beyond just the theoretical level. A small-scale demonstrator, in other words, facilitates practical access to the architectural function (ergonomics, scale etc.) and structural performance (strength, weight etc.), as well as the realities of fabrication, implementation, and the myriad of small design challenges that emerged during the prototyping process. The investigation was undertaken through a bespoke design-to-production system, comprising three conceptual stages; "Stitch", "Bend", and "Weave" (Figure 3).

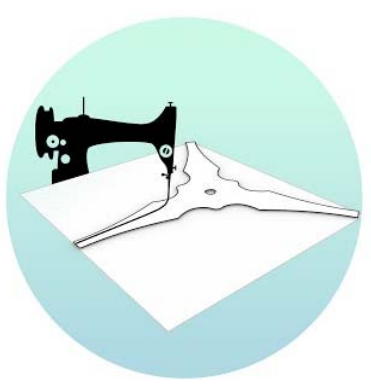

(a)

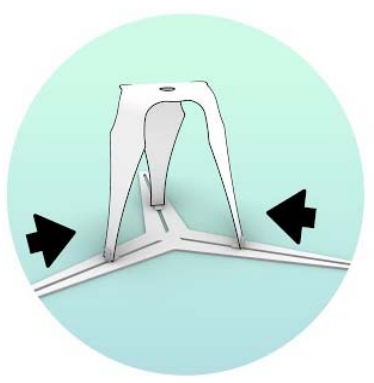

(b)

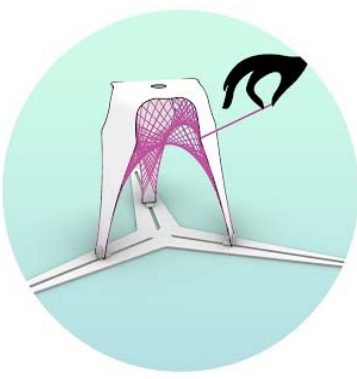

(c)

Figure 3. Concept: (a) Stitch: A tailored natural fiber textile is designed and produced in its flat form. This textile is infused with resin to create a fiber composite; (b) Bend: The activated polymer is formed into shape, enabled by specific fiber bending patterns; (c) Weave: This form becomes a permanent winding frame, upon which natural fibers are placed through coreless filament winding. Once cured, the TFP and CFW elements become a co-dependent functional and structural system in the form of a stool.

In this experimental approach, the selection of sustainable structural materials and fabrication methods took place before the step of defining the actual architectural design of a piece. In this case, applying the principles of "Materials as a Design Tool" philosophy [14] allowed for unrestricted shaping of the spatial form of the prototype, with particular focus on efficient use of fibrous composite material in an additive fabrication process, allowing for a reduction in the amount of production residues and eliminating the necessity of using disposable moulds made in subtractive fabrication processes such as CNC-milling.

\section{Materials and Methods}

\subsection{Flax Fibre and Epoxy Resin}

Research on natural fibers is a field of growing interest within the realm of the composites industry, primarily due to their production from annually renewable resources in low energy-intensive processes 
and their inherent potential for biodegradability and recycling at end of life; aspects which their synthetic counterparts cannot yet address as effectively at the time of writing [15-18]. This project builds upon the current trend as a means of establishing a viable structural application. As a result, non-twisted flax fiber rovings in two linear densities, 1200 Tex and 2400 Tex, have been selected for all production methods at the prototyping stage and sourced from the distributor, Group Depestele (Teillage Vandecandelaere 5, rue de l'église, 14540 Bourguebus, France).

Although equivalent research may be found with respect to biodegradable polymer matrices, material explorations were limited to only the fiber component of the composite. Fully synthetic Epoxy Resins ( 3 parts EPIKOTE Resin MGS RIMR $235+1$ part EPIKURE Curing Agent RIMH 237, Pot Life: $48 \mathrm{~h}$, all produced by Hexion Inc. and provided by Hexion Stuttgart GmbH, Fritz-Müller-Straße 114, 73730 Esslingen am Neckar, Germany) were therefore selected as the base matrix, due to prior experience with the products.

\subsection{Deductive Methodology}

The investigations detailed in this paper build upon the previously outlined case studies with respect to production techniques of fibrous composites and product design. The project consequently utilizes a deductive research method to assess whether the addition of TFP with CFW techniques can unlock further avenues for fibrous composites via the moldless design and production of a stool. This hypothesis is further broken down into sub-investigations, pertaining to each production method respectively.

\subsection{Design Process}

The physical design was developed in an iterative bottom-up process that overlaps material, fabrication, and global design investigations. Initial explorations began with rapid modelling of scaled paper models to establish global geometry. This was subsequently coupled with full scale material tests, the principles of which were extracted from pre-existing literature, such as the lamination theory $[19,20]$. These tests investigated localized performance, such as bending or stiffness, which were then extrapolated to the overall global geometry of the stool (Figure 4). These elements were then synthesized into a consolidated design prototype and tested for performance and function. The findings from each iteration were then interrogated, explored, and developed in subsequent versions of the design. Collectively, this formed an integrative design feedback loop.

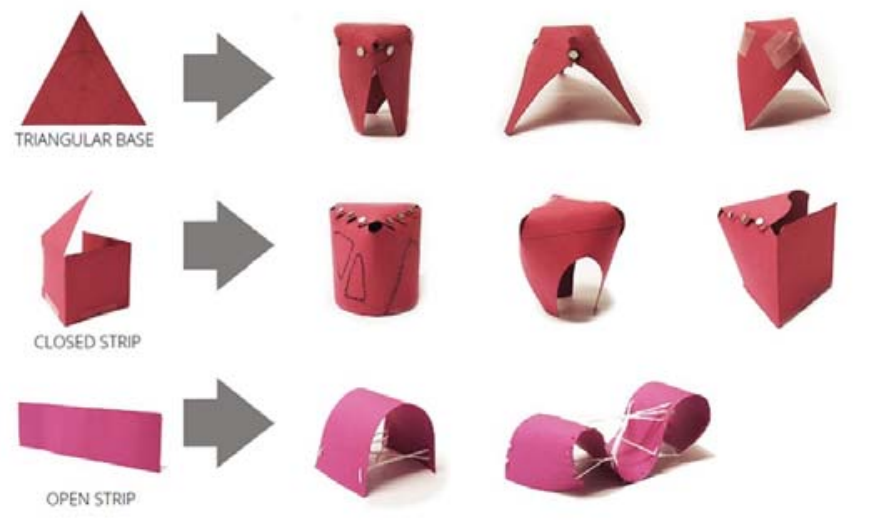

(a)

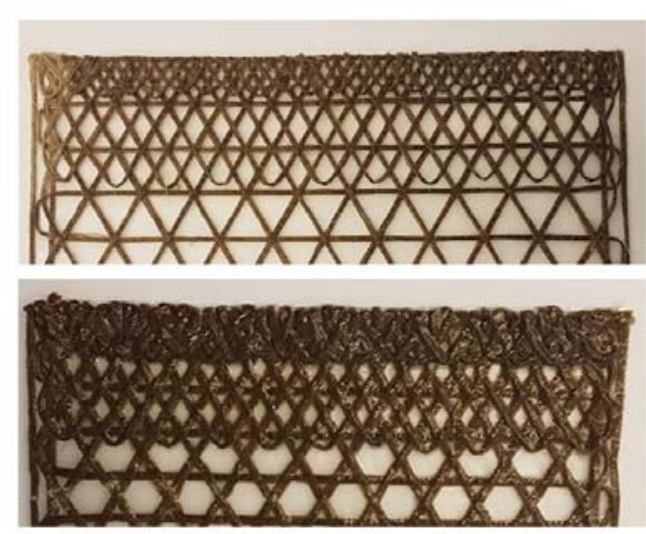

(b)

Figure 4. Design Process: (a) global design paper models; (b) material test samples with vacuum-infused resin. Top to bottom: 1200 Tex Fibre and 2400 Tex non-twisted roving. 
The main structural criteria that needed to be met by the design was to sustain the weight of a person inducing a load of minimum $800 \mathrm{~N}$. Final testing of the prototype was conducted by the authors.

\subsection{Production Process}

The production process was divided into two main parts; the manufacture of a bendable scaffold, produced flat and bent into shape using a custom rig (previously conceptualized as "Stitch" and "Bend") and the reinforcement of the scaffold via fiber winding to sustain the design load (termed "Weave"). Both parts were characterized by the use of the TFP and CFW processes, respectively, and detailed further below.

\subsection{Tailored Fiber Placement}

The TFP process makes use of an industrial grade embroidery machine that continuously lays filament material upon a thin, stretched textile mounted on a 2D movable frame [19]. In this project, dry, non-impregnated flax roving was laid using a 4-head embroidery machine of the brand Tajima, provided through the courtesy of Institute of Aircraft Design (IFB) at the University of Stuttgart. Filament material was also prepared by being spun in small quantities over a spool attached to the head of the machine. As fibers were laid down onto the textile, a fixed sewing needle and bobbin secured the fibers in place via a second threaded spool. The automated textile frame was numerically controlled and digitally programmed to follow any given path that was fed as a continuous polyline. In this project, a file with fiber path polylines was generated using CAD software Rhinoceros 3D. Moreover, primary fabrication parameters of the TFP process included the "stitch length" and "stitch width" of the thread, which collectively influenced the resolution of the final laid pattern. Exact values for these parameters were adjusted during prototyping and tabulated accordingly in the results section. Topological optimization in solidworks was used to inform the distribution of fibers along the designed preform.

The nature of this machine allowed an infinite set of customizable patterns to be made on a 2D surface (Figure 5a). In this context, a first sub-hypothesis is formulated as to whether tailored orientation of fibers in a cured state can allow for a controlled ability to bend a surface and achieve specific geometries.

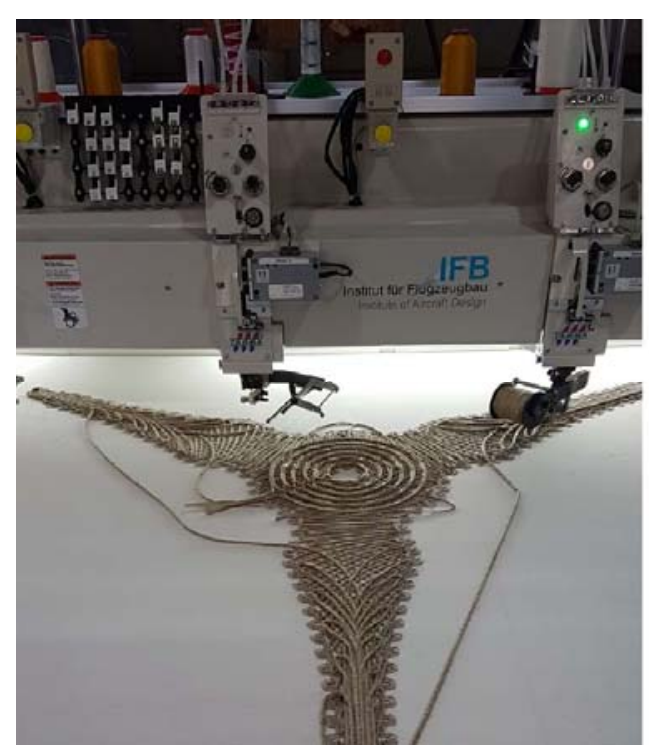

(a)

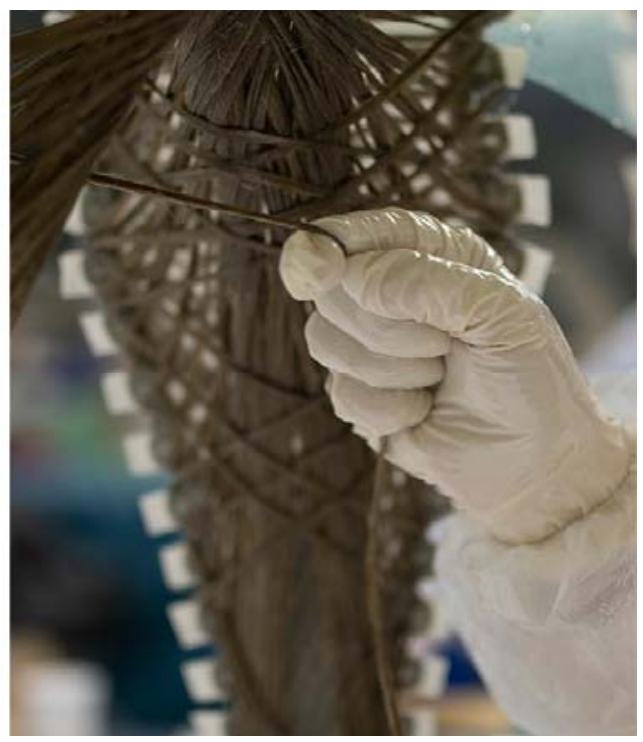

(b)

Figure 5. Production process, (a) TFP Machine Tajima, provided by the Institute of Aircraft Design (IFB), University of Stuttgart; (b) manual CFW technique. 


\subsection{Coreless Filament Winding}

CFW entails winding a continuous resin-impregnated filament material over a scaffold, typically via robotic automation. Due to the anisotropic nature of fibrous composites, an understanding of force flow in components becomes crucial to the fiber layup design. This pattern, termed "syntax", refers specifically to the sequence in which the continuous fiber is wound. Consequently, it can allow for a localized differentiation in material count, resistance to buckling failure, and varied geometry $[9,21]$. Since loading conditions for a small scale product design provide a simplified testing environment, stress flows and syntax design for the stool were set up empirically. The small scale also eliminated the need for robotic automation. Instead, the winding procedure for prototyping was carried out manually (Figure 5b).

This CFW technique relies heavily on keeping fibers taut upon the scaffold for maximum fiber-fiber interaction and performance [21,22], consequently placing additional pressures on the scaffold's stiffness. A second sub-hypothesis here questions whether such a technique can be used to permanently reinforce the $2 \mathrm{D}$ bent geometries generated via TFP methods.

\subsection{Fibre Impregnation Methods}

The mechanical properties of fiber composites are heavily influenced by the matrix-to-reinforcement ratio and the corresponding interface [23]. Due to a need for repeatable prototyping and controlled bending stiffness of the TFP surface, a reliable fiber impregnation method became necessary. A vacuum infusion process was consequently adopted to minimize behavioral discrepancies stemming from production. In this process, dry TFP preforms were manually infused with resin and subsequently sealed in an airtight bag. A negative pressure was applied by means of a vacuum pump, causing the resin to disperse evenly throughout the TFP preform and drain any excess material away from the sample. Upon full infusion, the sample was removed from the bag and left to cure.

For CFW, the fibers were continuously passed through a custom-built resin bath in order to absorb sufficient resin throughout the winding process, as shown in Figure 6 Upon completion, full curing took place and the prototype was demounted from the clamping rig.

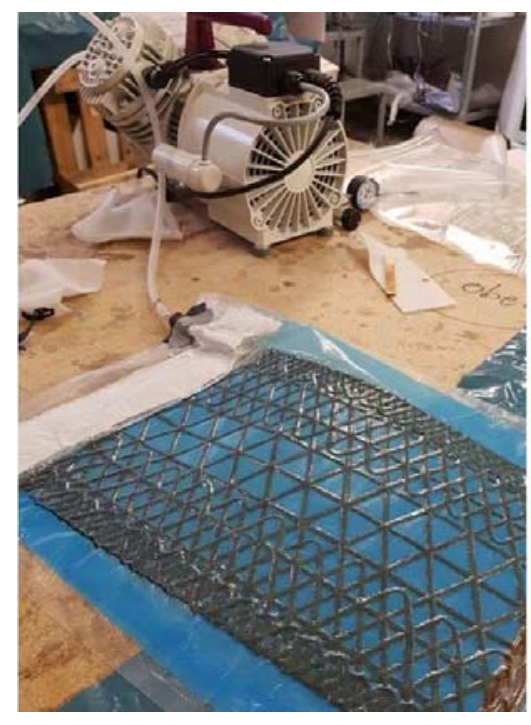

(a)

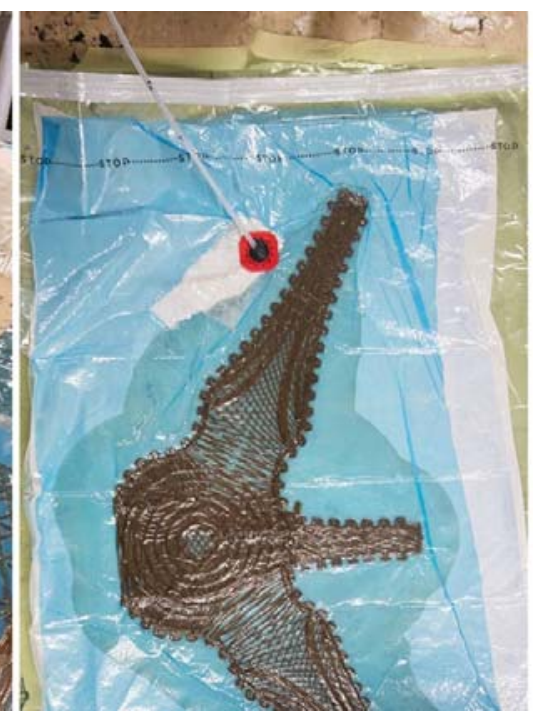

(b)

Figure 6. Fiber impregnation methods: (a) Resin infusion of test sample using vacuum pump and airtight sealing bag. Cotton layers and blue plastic film were used to soak excess resin and facilitate infusion; (b) infusion of prototype in process. 


\subsection{Analysis Criteria}

As a means to benchmark the prototyped outcomes, functional and performative criteria were restricted to three design conditions:

1. Ability to sustain the $800 \mathrm{~N}$ design load;

2. Minimalization of total weight of stool and corresponding material usage;

3. Qualitative comfort enabled by the geometry;

These conditions, coupled with design development, were tested, verified, and presented in further detail in the following sections as a means of validating the initial hypothesis.

\section{Results}

Performing the production process at the Institute of Aircraft Design (IFB) at the University of Stuttgart provided opportunities for interdisciplinary cross-pollination, where valuable insights were gained from the engineers. The TFP machine was used to produce a series of material test preforms and a first prototype to engage with the complexities of the machine and the specific data protocols required for production. After that, a final iteration was produced (Figure 7), which is the focus of this Results section. The final iteration was informed by these previous tests and addressed specific challenges of topological optimization, the TFP process, filament winding, and performance. Although somewhat independent, the integrated nature of the design and fabrication method meant that these elements were interrelated.

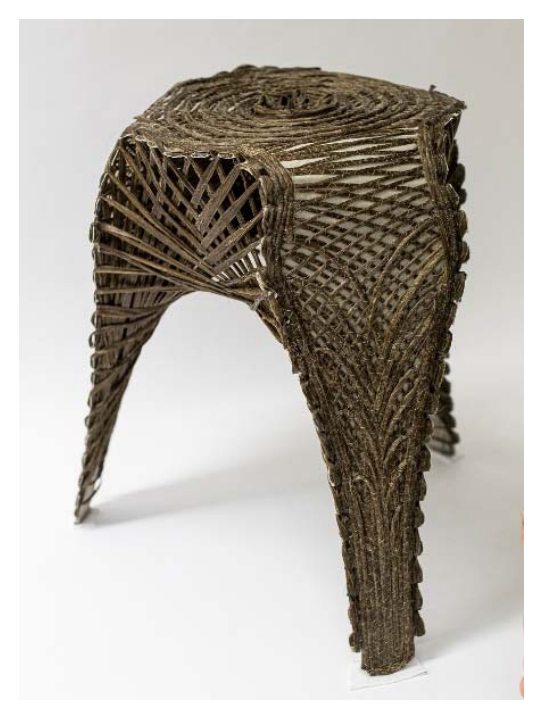

(a)

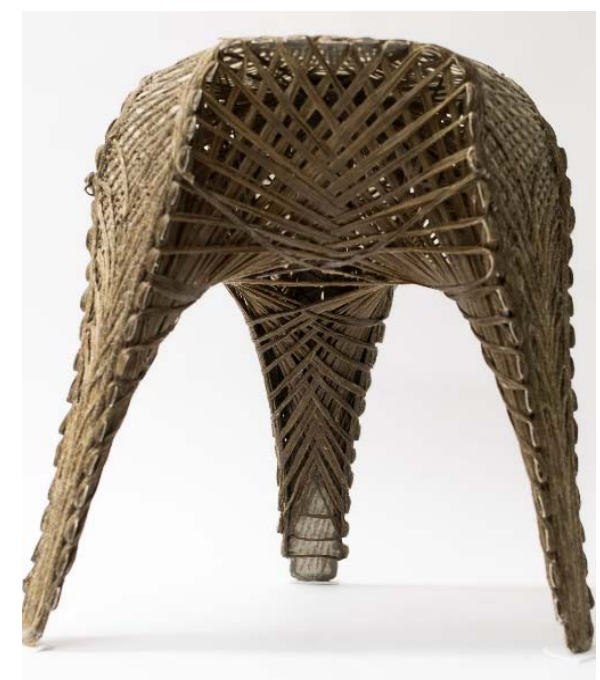

(b)

Figure 7. Final prototype: (a) view of the TFP Pattern; (b) view of the internal CFW syntax.

\subsection{Topological Optimization}

To better inform the placement of fibers in the TFP preform, the topological optimization platform in solidworks was used.

A simplified topology study tool was used to provide a rough visual estimation as to how the stresses distribute along the surface. The results allowed for a diagrammatic visualization of where the bulk of the material would be required for a given load configuration. Different amounts of material reduction were investigated for the same load case and edge condition. A selection of these studies can be seen in Figure 8. 

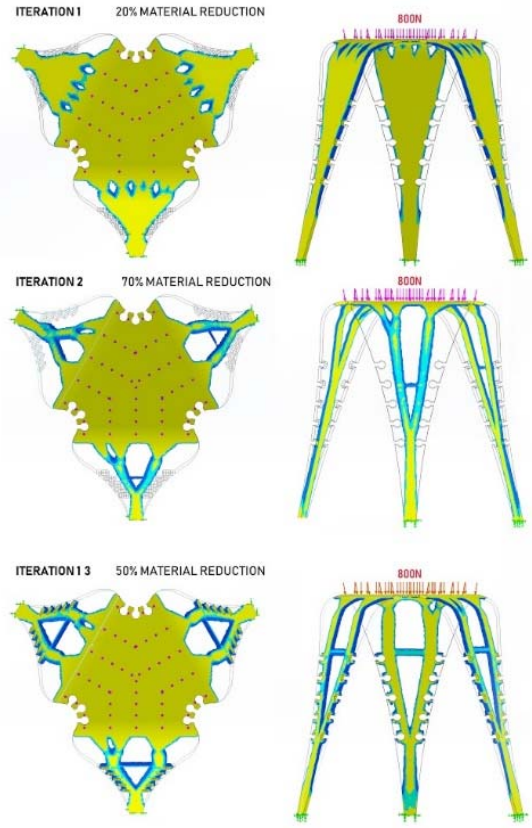

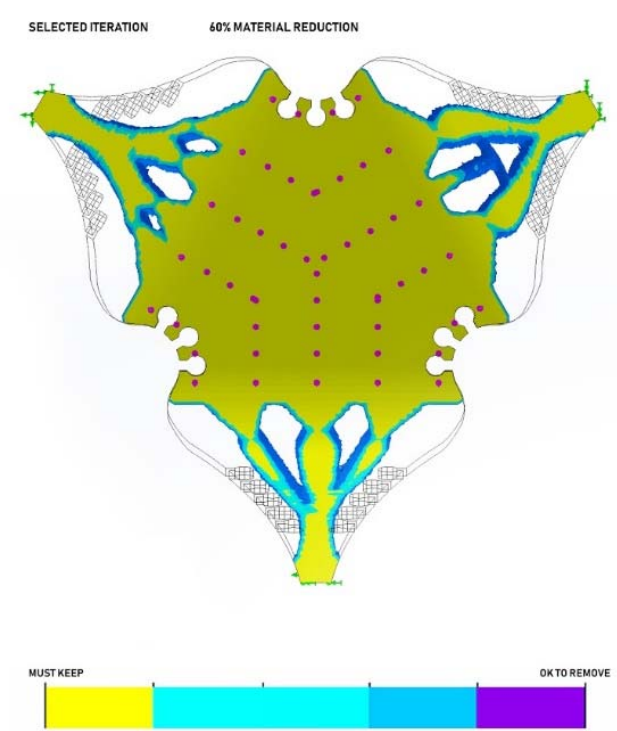

Figure 8. Topological optimization iterations.

For the topology study, an $8 \mathrm{~mm}$ thick single curved surface, modelled in Rhino3D, was prepared and imported accordingly. The specified surface thickness was imposed by the fabrication limitations of the Tajima embroidery machine used at the fabrication stage. The filament winding syntax was omitted from the simulation. As the exact mechanical properties of the used combination of flax roving and resin were difficult to pinpoint and were not available at the specific moment of conducting the fabrication experiment, the simulation was run using the built-in properties of glass fiber, providing that the desired stiffness criteria could be reached when lower mechanical strength of flax fiber in comparison to glass fiber was compensated by using sufficiently higher volume fractions [24].

An evenly distributed load of $800 \mathrm{~N}$ was applied to its horizontal seating surface. Winding pins were defined as a fabrication constraint, which forced the software to preserve the geometry during optimization.

The simulation was run using the best mass-to-stiffness goal criteria, for which various percentages, ranging from $30 \%$ to $70 \%$, were studied. No distinct outcome was favored. Instead, the simulations, all of which delivered similar results (such as in the associated figure), were used comparatively to identify the crucial areas transferring higher forces and thus requiring more material to be deployed.

Regions in yellow indicate places where material was needed most and those in blue indicate where material was needed the least. Throughout the iterations, it was possible to notice the emergence of a Y-shape distribution of material on the legs, which suggested that these areas had the biggest fiber cross-sections, i.e., structural layers. It was also possible to conclude that the seat area needed to remain dense. Other areas of the initial input surface were excluded, generating a new edge condition for the final design. Finally, this simulation did not provide the definitive visual pattern of the surface, but rather guided the TFP surface design.

\subsection{TFP Process}

\subsubsection{TFP Pattern}

In order to determine the fiber path pattern in the final TFP preform, with particular focus on enabling the flexible behavior of the bending zones, the anisotropic nature of the fibrous composite material required combining the results of the above-mentioned simplified optimization process with an interpretation of classical lamination theory (CLT) [17,18]. 
The finished TFP preform, after resin infusion process and complete curing, was supposed to be formed into a single curved surface and serve as the integrated frame in a later winding process. This required planning a diversified fiber path layout, which would reinforce and stiffen the seating area and leg endings, while guaranteeing a necessary flexibility of the composite material in the areas where the TFP preform was supposed to be bend (Figure 9).

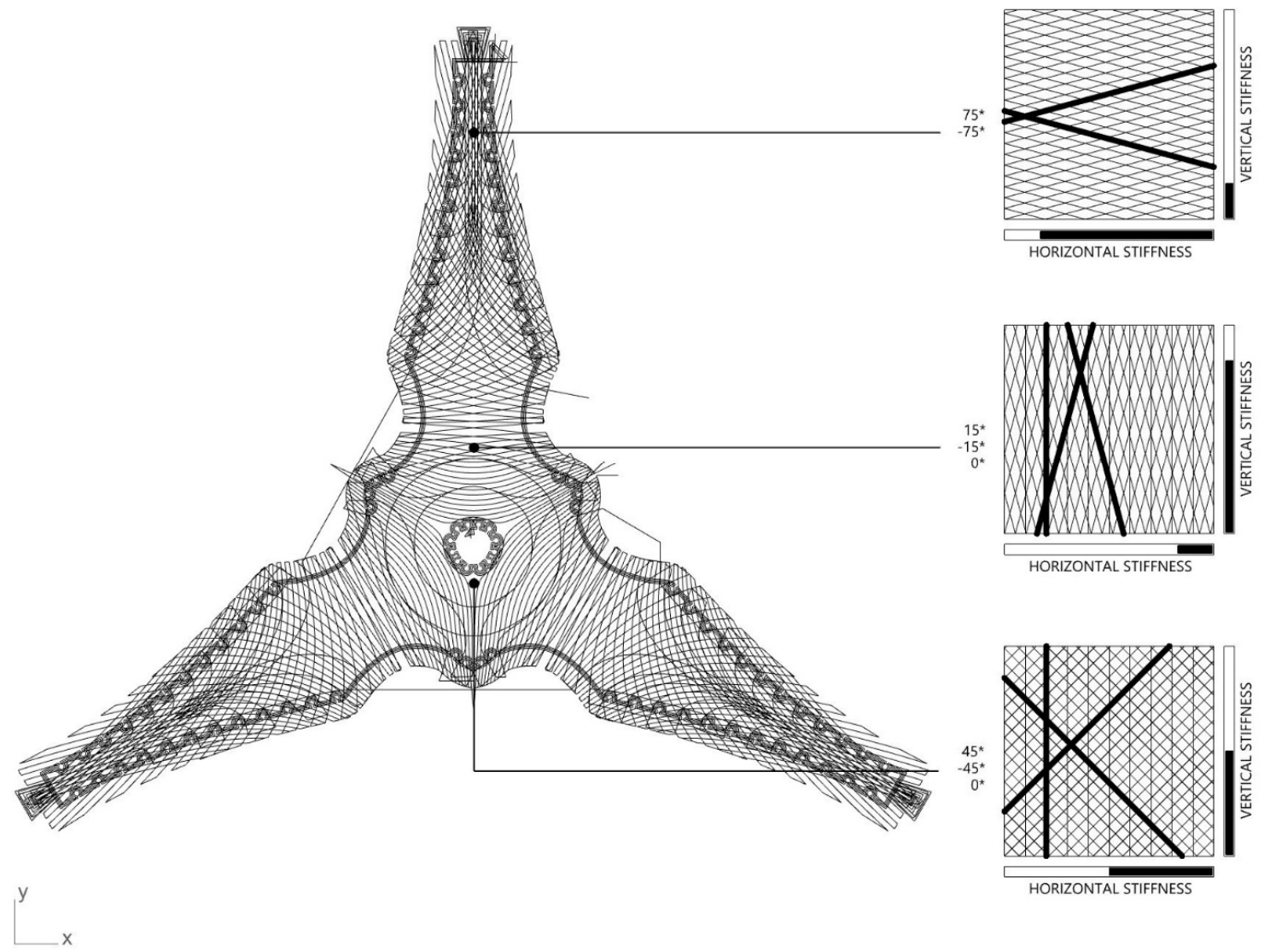

Figure 9. Final TFP pattern and interpretation of CLT.

Consequently, fiber paths in the seating area, oriented at $-45^{\circ}, 0^{\circ}$, and $45^{\circ}$, aim at creating a quasi-isotropic layup sequence, resulting in constant stiffness of the material regardless of the force direction, yet offering minimal elasticity of the surface for the purpose of seating comfort. Starting from the leg tips, in the leg areas, fiber paths were oriented, at $-75^{\circ}$ and $75^{\circ}$, thus almost parallel to the leg axis, in order to use material properties to the maximum when trying to develop a stiff structure that would not deflect under load. However, the closer to the hinge area, the more the fiber path angles smoothly translated to more perpendicular orientation, reaching $-15^{\circ}$ and $15^{\circ}$ in the center of the hinge areas.

Secondly, this core fiber path topology, designed according to structural performance of the stool model, was complemented with additional paths, which constituted further reinforcement and design details needed at a later stage of fiber winding.

The complete design of the fiber paths in the final TFP preform structure had to be adjusted to the fabrication requirements of the machine. Thus, according to the role each fiber path fragment played in both in the fabrication process, as well as later in the structural performance of the stool, they were grouped into three layers, which were fabricated consecutively one on top of the other, using 1200 TEX and 2400 TEX flax fibers by the embroidery machine. 
The final TFP pattern consisted of three layers:

1. Winding Pins Layer (Figure 10a).

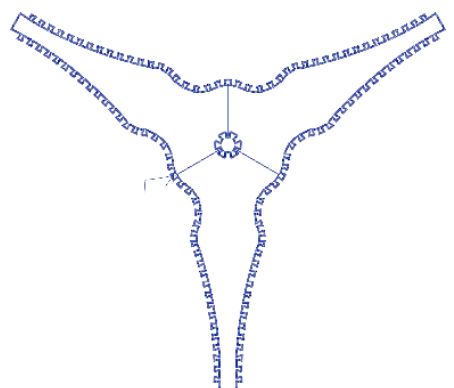

(a)

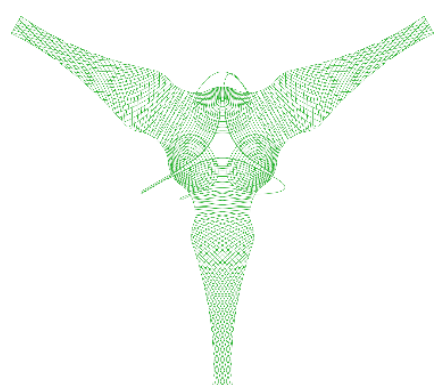

(b)

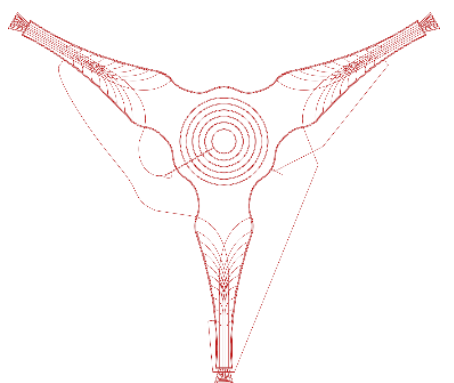

(c)

Figure 10. TFP layers: (a) Winding pins layer; (b) surface layer; (c) structural layer.

This layer was of special importance, since it provided the interface for the CFW process. The challenge at this step was determining the appropriate size of the pins. In order to guarantee visual integration of the pins in the final design of the FlexFlax, their dimensions should remain as modest as possible, but, at the same time, should be above the minimum fabrication size requirements of the TFP machine. The chosen geometry was a trapezoid of $2 \mathrm{~cm}$ (long base), $1 \mathrm{~cm}$ (short base), and $2 \mathrm{~cm}$ (height). To provide a delicate cross-section, a TFP machine preset of $1.5 \mathrm{~mm}$ stitch width was used for 1200 Tex flax fiber rovings. To guarantee the resolution of the winding pins, a $1 \mathrm{~mm}$ stitch length was set. Consequently, flax roving was sewn to the substrate with a higher number of stitches. However, this compromise resulted in a significantly longer production time for this stage of the TFP process.

2. Surface Layer (Figure 10b).

The surface layer, containing the fiber layout for the bending zone, was formed from 1200 Tex Flax roving with a stitch width of $1.5 \mathrm{~mm}$ and a stitch length of $7 \mathrm{~mm}$.

3. Structural Layer (Figure 10c).

The structural layer was fabricated using 2400 Tex roving, with a cross-sectional dimension of $3.6 \mathrm{~mm}$ (stitch width). In this final layer, a boundary curve was embedded in order to reinforce the thinner rovings during the fabrication process. The final TFP pattern was sewn into a cotton substrate of $1000 \times 1400 \mathrm{~mm}$. The used TFP machine settings, as well as the resulting fiber lengths for each layer, are presented in Table 1.

Table 1. Settings and results for the TFP process.

\begin{tabular}{cccccc}
\hline TFP & TEX & $\begin{array}{c}\text { Stitch Count } \\
\text { (stitches) }\end{array}$ & $\begin{array}{c}\text { Stitch Width } \\
\mathbf{( m m )}\end{array}$ & $\begin{array}{c}\text { Stitch Length } \\
\mathbf{( m m )}\end{array}$ & $\begin{array}{c}\text { Fiber Length } \\
\mathbf{( m )}\end{array}$ \\
\hline Layer 01 & 1200 & 31078 & 1.5 & 1 & 31 \\
Layer 02 & 1200 & 8725 & 1.5 & 7 & 54 \\
Layer 03 & 2400 & 6838 & 3.6 & 7 & 38 \\
Total & - & 46641 & - & - & 123 \\
\hline
\end{tabular}

\subsubsection{Vacuum Infusion}

After the accomplished TFP fabrication of the preforms, the excess of the substrate fabric was trimmed, and resin was applied through the vacuum infusion process explained in Section 2.7. The used resin system was EPIKOTE Resin MGS RIMR 235 with EPIKURE Curing Agent RIMH 237, produced by 
Hexion Inc. Standard polythene vacuum bags of $130 \times 90 \mathrm{~mm}$, commonly available in the market, were used in conjunction with a vacuum pump (model P3 produced by R\&G Faserverbundwerkstoffe: max. $55 \mathrm{l} / \mathrm{min}$. at 0.900 bar vacuum). One sheet of cotton textile was placed underneath the sample and one layer of perforated release film (model P1 produced R\&G Faserverbundwerkstoffe) was placed on top. The dimensions of the sheets were the same size as the bag. Their presence ensured an even distribution of air pressure, as well as absorption of the excess of resin from the undesired areas. After the infusion process, the preforms underwent a curing process at room temperature for $48 \mathrm{~h}$.

\subsection{Coreless Filament Winding Process}

\subsubsection{Fabrication Clamp}

A simple clamping rig (Figure 11) was required to stabilize the bending active TFP preform for winding. For the purposes of this project, timber was milled in a shape that corresponds to the tripod stool morphology. Each foot was held by an adjustable timber socket. These sockets can rotate vertically and slide along defined rails. This allows the bending active element to naturally find a stable geometry, as well as enable the rig to be reused and reconfigured to fabricate stools of various shapes, sizes, and heights.

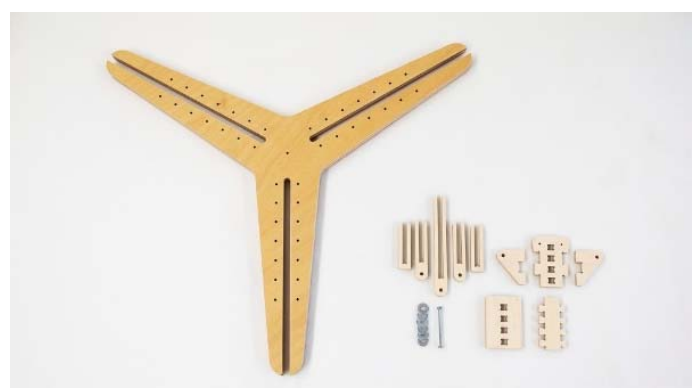

(a)

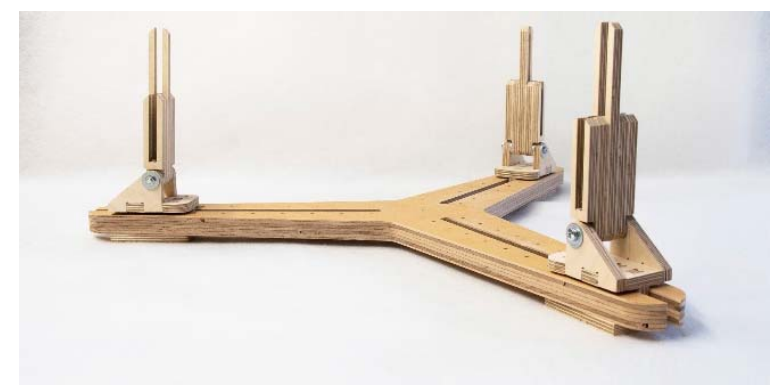

(b)

Figure 11. Fabrication clamp: (a) Pieces prior to assembly; (b) assembled clamp.

\subsubsection{Syntax Design}

The CFW syntax used on the prototype consisted of three layers that served different strategies:

1. A first Spine Syntax transferred forces from the center of the seat to each leg, locking the bending zone in place (Figure 12a);

2. A second Bracing Syntax braced each leg individually to ensure fiber-fiber interaction on the previous syntax (Figure 12b);

3. A third and final Locking Syntax connected the legs to one another, to provide stability to the stool when it is being sat on, and the feet try to thrust apart from each other. Additionally, this layup provides geometric depth to the structure in an evocative anticlastic shape; a geometry that is extremely difficult and costly to create using traditional fabrication methods (Figure 12c).

The complete syntax layup was initially developed on 1:5 scale models and then wound using dry, non-impregnated fibers on the full-scale prototype. Once the sequences were satisfactorily defined, the prototype was wound using a resin bath impregnation system, described previously in Section 2.7. The winding process was done manually, after which the prototype was cured for $48 \mathrm{~h}$ at room temperature. 


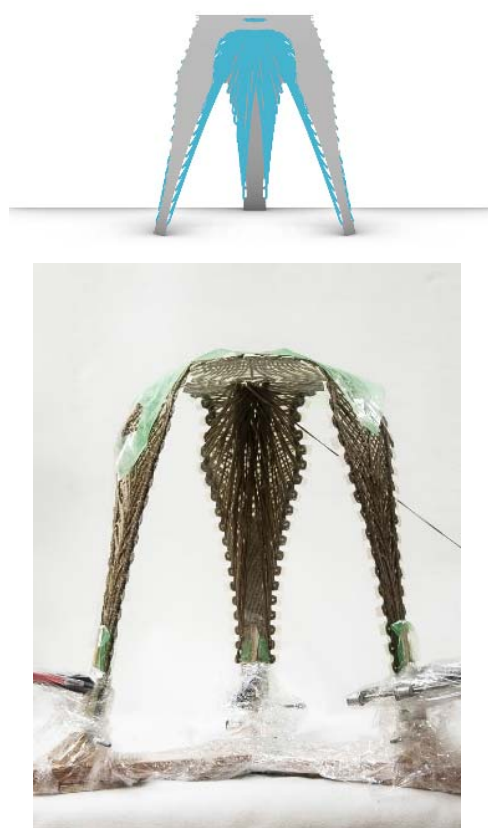

(a)

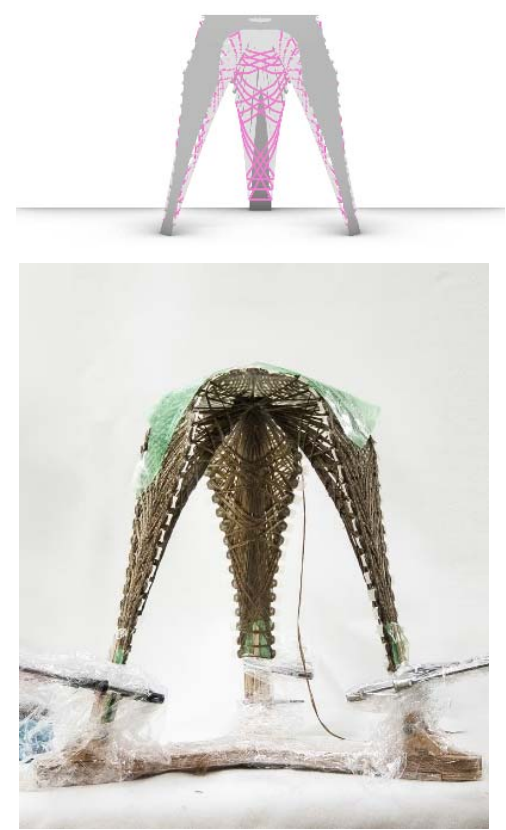

(b)

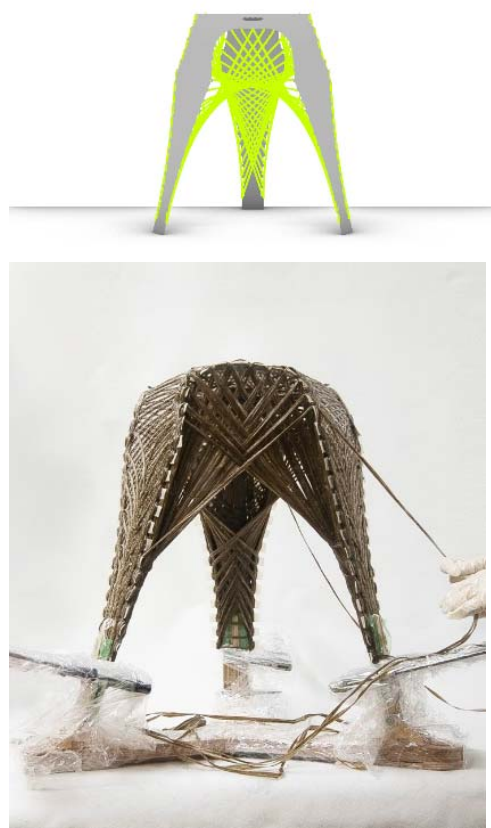

(c)

Figure 12. Syntax layers: (a) Spine layer; (b) bracing layer; (c) locking layer.

\subsection{Performance}

Once curing was completed, the performance of the FlexFlax could be assessed. As mentioned previously, this consisted of the analysis of the material usage and the ability of the stool to withstand loads of minimum $800 \mathrm{kN}$, i.e., an $80 \mathrm{~kg}$ person.

\subsubsection{Material Count}

The final weight of this prototype was 1080 grams. Tables 2 and 3 present, respectively, the amount of fiber and resin used. It is important to note that it was not possible to assess exact losses of the material in the fabrication process, especially in regards to the resin.

Table 2. Fiber usage of final FlexFlex prototype.

\begin{tabular}{cc}
\hline Process & $\begin{array}{c}\text { Fiber Length } \\
(\mathbf{m})\end{array}$ \\
\hline TFP & 123 \\
Filament Winding & 190 \\
Total & 313 \\
\hline
\end{tabular}

Table 3. Resin usage of final prototype.

\begin{tabular}{cccc}
\hline Type of Process & Resin Type & Ratio & $\begin{array}{c}\text { Resin Usage } \\
\text { (g) }\end{array}$ \\
\hline Vacuum Infusion & $\begin{array}{c}\text { EPIKOTE 235 and } \\
\text { EPIKURE 237 } \\
\text { EPIKOTE 235 and } \\
\text { EPIKURE 237 }\end{array}$ & $3: 1$ & 780 \\
Filament Winding & - & - & 950 \\
Total & \begin{tabular}{c} 
EPI \\
\hline
\end{tabular}
\end{tabular}

The final dimensions of the stool base were approximately $40 \times 40 \mathrm{~cm}$, with a height of $45 \mathrm{~cm}$. The three legs formed the shape of an equilateral triangle, with a side length of approximately $42 \mathrm{~cm}$ $( \pm 0.5 \mathrm{~cm})$. 


\subsubsection{Seating Test}

The structural performance of the stool was done by conducting a seating test with participation of persons of different weight. Despite the light weight of the stool, volunteers whose weight ranged from $55 \mathrm{~kg}$ to $85 \mathrm{~kg}$ could successfully sit on the stool (Figure 13). Meanwhile, only slight elastic deflection of the stool feet for the highest load was observed. At the load of $85 \mathrm{~kg}$, deflection at the stool feet ends measured $0.7 \mathrm{~cm}$ (initial distance between leg feet: $41.7 \mathrm{~cm}$; during seating: $42.5 \mathrm{~cm}$ ) (Figure 14). These tests also allowed for estimation of qualitative comfort of the stool. The stool demonstrated the same stiffness independently from the direction from which it was sat on. Both the number of legs and the span of approximately $42 \mathrm{~cm}( \pm 0.5 \mathrm{~cm})$ between them was sufficient in providing stability of the stool during the test. As planned, the seating surface demonstrated limited elastic behavior contributing to the overall seating comfort of the user. Simultaneously, the elastic behavior was restricted to the seating area only and did not affect the performance of the legs, which remained stiff.

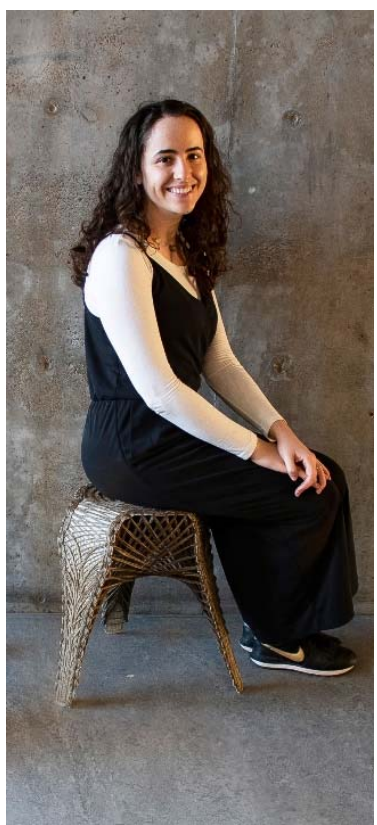

(a)

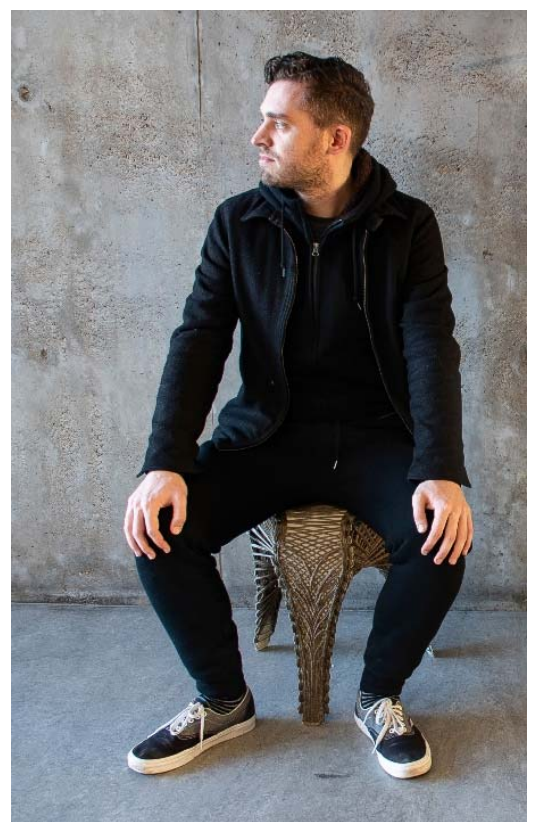

(b)

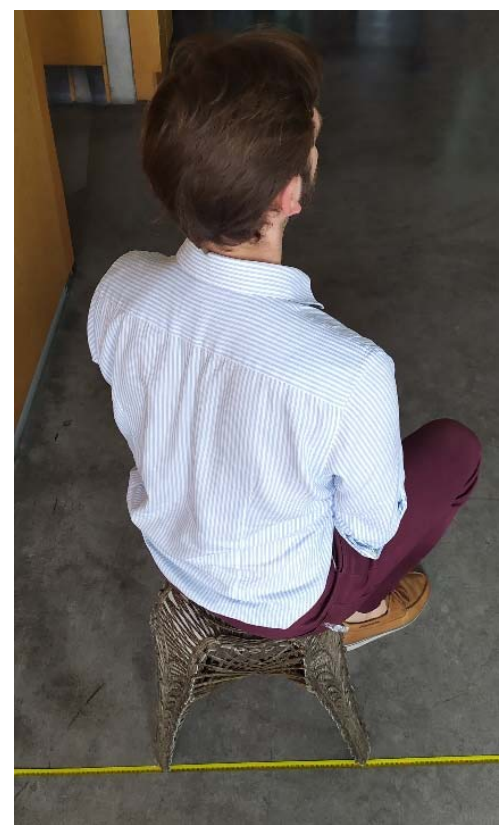

(c)

Figure 13. Preview of the seating test: (a) $55 \mathrm{~kg}$ user; (b) $70 \mathrm{~kg}$ user; (c) $85 \mathrm{~kg}$ user.

Such low deflection of the stool indicates its capabilities of withstanding even greater loads. However, the validity of this hypothesis can only be proven by submitting the stool to destructive tests conducted with loads greater than $800 \mathrm{~N}$. Currently, the presented stool is the only demonstrator of the FlexFlax fabrication process realized by us and a destructive compression test has not been performed on it yet, but rather an experimental validation of the whole hypothesis through physical application of human weight, which ranged between $5300 \mathrm{~N}$ and $800 \mathrm{~N}$, as discussed. A destructive test will be conducted in near future work once a greater number of prototypes, of the same dimensions and with the same quantity of composite material, is fabricated in order to obtain comparable results, which will be published in a separate publication. 


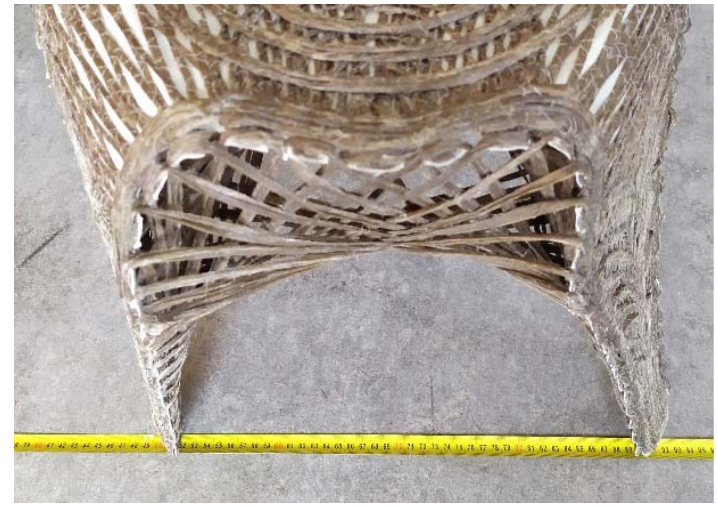

(a)

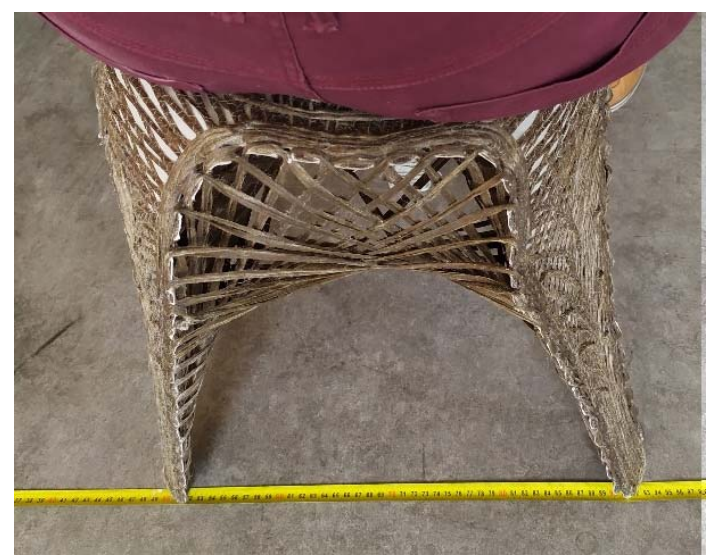

(c)
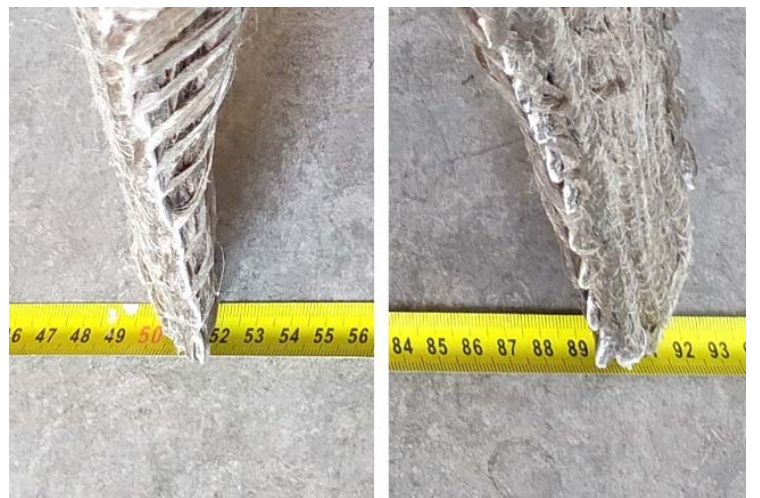

(b)
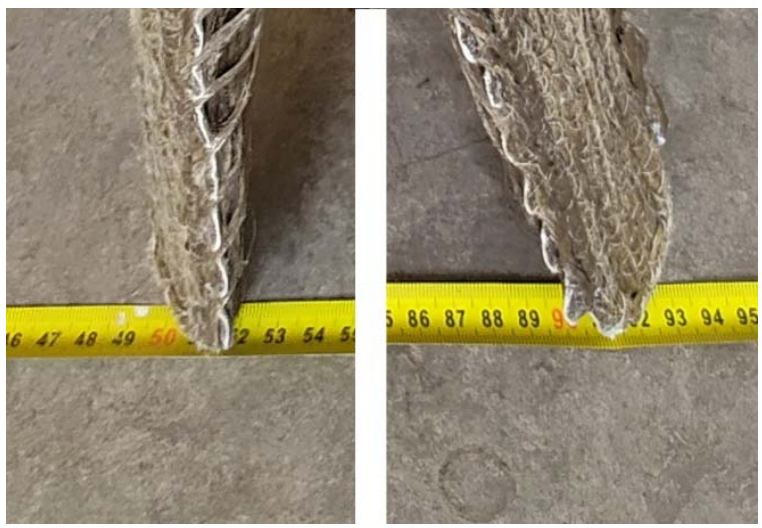

(d)

Figure 14. Preview of the seating test with $85 \mathrm{~kg}$ user: (a) and (b) before sitting: $41.7 \mathrm{~cm} \mathrm{span;} \mathrm{(c)} \mathrm{and}$ (d) during sitting: $42.5 \mathrm{~cm}$ span.

\section{Discussion}

The aim of the project was to explore the potential of combining TFP and CFW techniques for the purpose of realization of spatial structures without the necessity of using complex molds or frames. The successful implementation of these techniques is demonstrated in a high-performance design object, which can support approximately 80 times its own weight. This object was realized by a novel digital design and fabrication workflow, which are expressed by a unique material tectonic.

The TFP preform, embroidered on a cotton substrate, predictably bends in the desired zones with similar bending radii for each leg. The seat and legs of the realized stool offered sufficient structural stiffness and aesthetic richness informed by the fiber pattern design. The CFW syntax in the interior of the stool offered a secondary layer of geometrical and formal complexity to complement the exterior. Collectively, the fiber patterns and ordinary tripod geometrical typology familiarized the unusual material expression. The FlexFlax visually recalls woven structures, such as ratan, but in a new material-informed design expression (Figure 15).

Although a simplified topological optimization strategy used in this experiment was sufficient for estimating NFRP material quantities and its distribution in the structure, with the aim of reaching desired structural strength, it is clear that further research using this approach and further advanced approaches are needed to investigate and deliver exact data about the weight-to-strength ratio, which can be reached using the FlexFlax fabrication approach. At this step, the prototype still remains a demonstrator of Materials as a Design Tool philosophy [14], rather than providing exact data about performance of NFRP structures. Undoubtedly, since the FlexFlax workflow was established in the presented paper, the following steps should focus on including more detailed structural simulation, 
considering exact fiber paths and optimization of the fiber infusion and winding processes. This would allow for exact control over the fiber-to-resin ratio and, consequently, mechanical properties of the generated NFRP. The above-mentioned improvement would allow for realizing several comparable prototypes and estimating their maximum strength through a compression test.

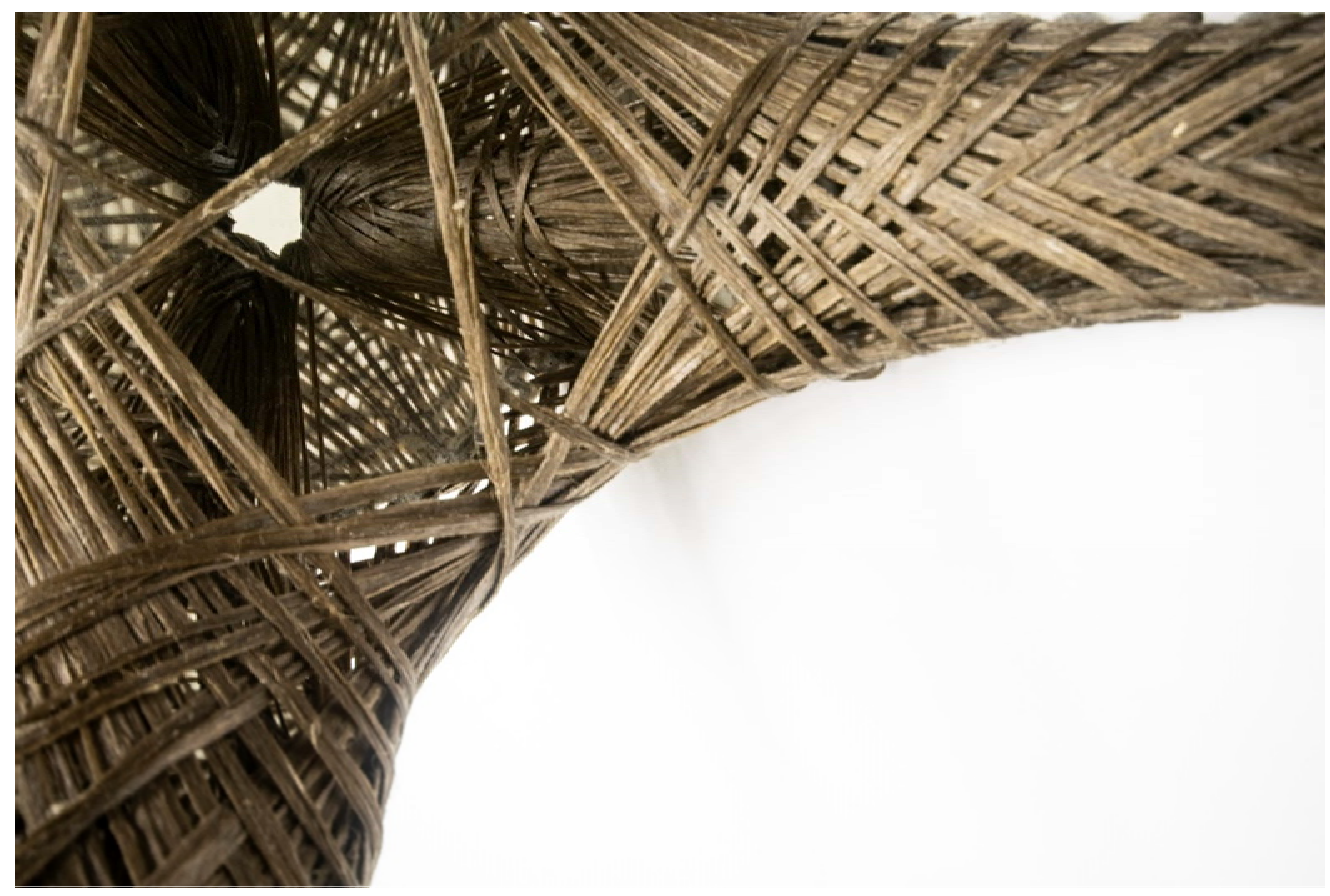

Figure 15. Final FlexFlax stool prototype: Detail of the underside.

Nonetheless, the high performance comes at the cost of a multi-method fabrication system that may become labor-intensive. Automation potentials are currently under study to overcome those potential drawbacks. There are several aspects that could still be refined, particularly with regards to the CFW step of the process. The use of prepreg rovings at this step was not explored during this project, but it is predicted that this method could decrease fabrication complexity and reduce time consumed during the winding process. The curing time could also be further reduced, both by choosing an alternative resin system characterized by a shorter pot life and by curing the components in an autoclave.

Considering all the above-mentioned conditions, it is justified to speculate about possibilities of application of this system at an architectural scale, in both discrete and continuous natural fiber application. Regarding the discretized design, a controlled prefabrication environment could help with material fabrication constraints. The light weight, in conjunction with a small-scale building component, makes it suitable for modular sustainable building constructions. Finally, as a continuous system, this process could enable partial prefabrication with on-site continuous winding realized by mobile robots [25]. Such an approach would allow for realization of larger building elements with fewer fragile connections between them. These are the avenues of research that will likely produce rich new architectural modes of production for future sustainable building systems.

Author Contributions: V.C.M., S.C., and C.v.d.H. contributed equally to this paper. Concept, design, methods, representation, prototyping, and testing of the project, as well as writing of the paper, was done by the trio together. H.D. (BioMat Department director) and P.B. (BioMat research associate) gave the students all prerequisite know-how in the field of biocomposites and sustainable architectural building elements, edited the paper, and supervised the educational course Material Matter Lab (Material and Structure, winter semester 2019/2020), in which this prototype was produced. All authors have read and agreed to the published version of the manuscript. 
Funding: The project was partially supported by the Deutsche Forschungsgemeinschaft (DFG, German Research Foundation) under Germany's Excellence Strategy EXC 2120/1-390831618.) The project was also partially supported by the Agency for Renewable Resources (FNR) under the Federal Ministry of Food and Agriculture (BMEL) throughout the research project LeichtPro: Pultruded load-bearing lightweight profiles from natural fiber composites (FKZ:22027018), managed by H.D.

Acknowledgments: The project was developed in the seminar Material Matter Lab (Material and Structure, winter semester 2019/2020), offered by BioMat (The Department of Biobased Materials and Materials Cycles in Architecture) ITKE at the University of Stuttgart under supervision of Hanaa Dahy and tutoring of Piotr Baszyński and Sophie Luz. We would also like to show our gratitude to Peter Middendorf, Stefan Carosella, and Benjamin Grisin at the IFB (Institute of Aircraft Design) at the University of Stuttgart for the opportunity to access their machines and for the intensive technical support and guidance throughout the process. The flax rovings used in the project were provided at the courtesy of Group Depestele, Teillage Vandecandelaere 5, rue de l'église, 14540 Bourguebus, France. The resin system used in the project was provided at the courtesy of Hexion Stuttgart GmbH, Fritz-Müller-Straße 114, 73730 Esslingen am Neckar, Germany

Conflicts of Interest: The authors declare no conflict of interest.

\section{References}

1. Pomponi, F.; Moncaster, A. Embodied carbon mitigation and reduction in the built environment-What does the evidence say? J. Environ. Manag. 2016, 181, 687-700. [CrossRef] [PubMed]

2. Abergel, T.; Dean, B.; Dulac, J. Towards a Zero-Emission, Efficient, and Resilient Buildings and Construction Sector: Global Status Report 2017; UN Environment International Energy Agency: Paris, France, 2017.

3. Lehne, J.; Preston, F. Making Concrete Change: Innovation in Low-Carbon Cement and Concrete; Chatham House Rep. Energy Environment Resour. Dep.: London, UK, 2018; pp. 1-66.

4. Menges, A. Computational Material Culture. Archit. Des. 2016, 86, 76-83. [CrossRef]

5. Dahy, H. Natural Fibre-Reinforced Polymer Composites (NFRP) Fabricated from Lignocellulosic Fibres for Future Sustainable Architectural Applications, Case Studies: Segmented-Shell Construction, Acoustic Panels, and Furniture. Sensors 2019, 19, 738. [CrossRef] [PubMed]

6. Menges, A.; Knippers, J. Fibrous Tectonics. Archit. Des. 2015, 85, 40-47. [CrossRef]

7. Richter, E.; Spickenheuer, A.; Bittrich, L.; Uhlig, K.; Heinrich, G. Applications of variable-axial fibre designs in lightweight fibre reinforced polymers. In Proceedings of the Materials Science Forum; Trans Tech Publications: Bäch, Switzerland, 2015; Volume 825, pp. 757-762.

8. Dahy, H. Biocomposite materials based on annual natural fibres and biopolymers-Design, fabrication and customized applications in architecture. Constr. Build. Mater. 2017, 147, 212-220. [CrossRef]

9. Prado, M.; Dorstelmann, M.; Schwinn, T.; Menges, A.; Knippers, J. Core-Less Filament Winding: Robotically Fabricated Fiber Composite Building Components. 2014. Available online: https:/www.researchgate.net/ publication/272784909_Core-Less_Filament_Winding (accessed on 4 May 2020).

10. Aldinger, L.; Margariti, G.; Körner, A.; Suzuki, S.; Knippers, J. Tailoring Self-Formation fabrication and simulation of membrane-actuated stiffness gradient composites. 2018. Available online: https://www.researchgate.net/publication/326552014_Tailoring_Self-Formation_fabrication_and_ simulation_of_membrane-actuated_stiffness_gradient_composites (accessed on 4 May 2020).

11. Felbrich, B.; Frueh, N.; Prado, M.; Saffarian, S.; Solly, J.; Vasey, L.; Knippers, J.; Menges, A. Multi-Machine Fabrication: An Integrative Design Process Utilising an Autonomous UAV and Industrial Robots for the Fabrication of Long Span Composite Structures. 2017. Available online: https://www.researchgate. net/publication/321026463_Multi-Machine_Fabrication_An_Integrative_Design_Process_Utilising_an_ Autonomous_UAV_and_Industrial_Robots_for_the_Fabrication_of_Long_Span_Composite_Structures (accessed on 4 May 2020).

12. Dahy, H.; Petrs, J.; Baszynski, P. Design and Fabrication of two 1:1 Architectural Demonstrators based on Biocomposites from Annually Renewable Resources displaying a Future Vision for Sustainable Architecture. In FABRICATE 2020; UCL: London, UK, 2020; ISBN 978-1-78735-812-6.

13. Duque Estrada, R.; Wyller, M.; Dahy, H. Aerochair Integrative design methodologies for lightweight carbon fiber furniture design. In Proceedings of the 37th eCAADe and 23rd SIGraDi Conference-Architecture in the Age of the 4th Industrial Revolution, Porto, Portugal, 11-13 September 2019; Volume 1, pp. 691-700.

14. Dahy, H. 'Materials as a Design Tool' Design Philosophy Applied in Three Innovative Research Pavilions Out of Sustainable Building Materials with Controlled End-Of-Life Scenarios. Buildings 2019, 9, 64. [CrossRef] 
15. Van der Werf, H.M.G.; Turunen, L. The environmental impacts of the production of hemp and flax textile yarn. Ind. Crops Prod. 2008, 27, 1-10. [CrossRef]

16. González-García, S.; Hospido, A.; Feijoo, G.; Moreira, M.T. Life cycle assessment of raw materials for non-wood pulp mills: Hemp and flax. Resour. Conserv. Recycl. 2010, 54, 923-930. [CrossRef]

17. Stevens, C. Industrial Applications of Natural Fibres: Structure, Properties and Technical Applications; John Wiley \& Sons: Hoboken, NJ, USA, 2010; Volume 10.

18. Pickering, K.L.; Efendy, M.G.A.; Le, T.M. A review of recent developments in natural fibre composites and their mechanical performance. Compos. Part A Appl. Sci. Manuf. 2016, 83, 98-112. [CrossRef]

19. Herakovich, C.T. Composite Materials: Lamination Theory. In Wiley Encyclopedia of Composites; American Cancer Society: Atlanta, GA, USA, 2012; pp. 1-5. ISBN 978-1-118-09729-8.

20. Fan, M.; Fu, F. Advanced High Strength Natural Fibre Composites in Construction; Woodhead Publishing: Sawston, UK, 2016.

21. Aschenbrenner, L.; Temmen, H.; Degenhardt, R. Tailored Fibre Placement Technology-Optimisation and Computation of CFRP Structures. 2007. Available online: https:/www.researchgate.net/publication/ 224985701_Tailored_Fibre_Placement_optimization_tool (accessed on 4 May 2020).

22. Knippers, J.; La Magna, R.; Menges, A.; Reichert, S.; Schwinn, T.; Waimer, F. ICD/ITKE Research Pavilion 2012: Coreless Filament Winding Based on the Morphological Principles of an Arthropod Exoskeleton. Archit. Des. 2015, 85, 48-53. [CrossRef]

23. Rana, S.; Fangueiro, R. Fibrous and Textile Materials for Composite Applications; Springer: Singapore, 2016; ISBN 978-981-10-0232-8.

24. Duflou, J.R.; Yelin, D.; Van Acker, K.; Dewulf, W. Comparative Impact Assessment for Flax Fibre versus Conventional Glass Fibre Reinforced Composites: Are Bio-Based Reinforcement Materials the Way to Go? CIRP Ann. 2014, 63, 45-48. [CrossRef]

25. Yablonina, M.; Prado, M.; Baharlou, E.; Schwinn, T.; Menges, A. Mobile Robotic Fabrication System for Filament Structures. In Fabricate 2017; Menges, A., Sheil, B., Glynn, R., Skavara, M., Eds.; UCL Press: London, UK, 2017; pp. 202-209. ISBN 978-1-78735-000-7.

(C) 2020 by the authors. Licensee MDPI, Basel, Switzerland. This article is an open access article distributed under the terms and conditions of the Creative Commons Attribution (CC BY) license (http://creativecommons.org/licenses/by/4.0/). 